\title{
PARTICIPAÇÃO E CONTROLE SOCIAL EM UM DISTRITO SANITÁRIO DE FLORIANÓPOLIS-SC ${ }^{1}$
}

\author{
PARTICIPATION AND SOCIAL CONTROL AT A SANITARY DISTRICT OF \\ FLORIANÓPOLIS - SC
}

Deidvid de Abreu ${ }^{2}$

\begin{abstract}
RESUMO
Este artigo apresenta e discute questões relativas à participação e ao controle social do Distrito Sanitário Continente do município de Florianópolis/SC, sob a ótica dos integrantes de dois dos conselhos locais de saúde. Estes espaços, embora considerados privilegiados para tal fim, na opinião de grande parte dos entrevistados têm seu trabalho e interferência ainda muito restritos. Apontam a necessidade de seu fortalecimento, principalmente com a participação de novos atores, articulada a formações permanentes. A partir da análise de conteúdo, método utilizado no tratamento dos dados, outras questões foram suscitadas nas narrativas dos entrevistados; dentre elas, a falta de participação dos usuários do SUS e dos próprios profissionais da saúde, a falta de legitimidade desses conselhos e a relação fragmentada entre eles e o Conselho Municipal de Saúde de Florianópolis.
\end{abstract}

PALAVRAS-CHAVE: Participação. Controle social. Conselho Local de Saúde. Cidadania.

\begin{abstract}
This paper presents and discusses questions related to the participation and to the social control of the Sanitary District of Continente of the City of Florianópolis, SC, from the point of view of two members of the local Healthy Councils. Both places, though considered privileged for their purposes, present some efficiency constraints, according to the opinion of most the people interwied. Those Councils need improvements such as the participation of new actors articuled to permanent training programs. From the analysis of the data content, the method used in the data treatment, other subjects were elicited in the interviews. Among them, the absence of the participation of the Unified Health System (SUS) users and the health professionals themselves, the lack of legitimacy of the Councils and the biased relationship between them and the City of Florianópolis Healthy Council.
\end{abstract}

KEYWORDS: Participation. Social Control. Health Local Councils. Citizenship.

\footnotetext{
${ }^{1}$ Devemos salientar que em sua prática profissional o Sujeito 3 não exerce o papel de Autoridade Sanitária.

${ }^{2}$ Assistente social da Secretaria Municipal de Saúde de Florianópolis, especialista em Saúde da Família (UFSC); mestrando em Saúde Mental e Atenção Psicossocial (UFSC). Telefone 55483262 0719, email: deidvid@hotmail.com.
}

Serv. Soc. \& Saúde, Campinas, SP v. 11, n. 2 (14) p. 245-268 jul./dez. 2012 ISSN 1676-6806 


\section{PRIMEIRAS PALAVRAS...}

Discutir a participação e o controle social em conselhos locais de saúde sob a ótica dos conselheiros é aprofundar-se no campo de relações sociais que afetam cada sujeito envolvido, os processos que se dão nesses espaços, bem como os significados por eles percebidos e aplicados aos acontecimentos cotidianos.

A participação não é um conceito novo. Por sua relação intrínseca com o tempo histórico, porém, com as constantes modificações sociais e políticas no cenário brasileiro e mundial pode ser considerada sempre nova se reconhecermos que se constitui na relação sujeito-contexto, a qual, dependendo dessas variáveis, sofre alterações significativas. Para a efetivação do Sistema Único de Saúde - SUS - como instituição verdadeiramente pública e participativa, que busca a promoção da cidadania e a conquista de melhores indicadores de saúde, são necessários estudos que qualifiquem os processos participativos locais e democráticos em saúde.

Buscando conhecer quem são e o que falam os atores sociais, tanto os da sociedade civil, quanto os trabalhadores, gestores e prestadores de serviço que integram dois dos conselhos locais de saúde do Distrito Sanitário Continente, do município de Florianópolis/SC, objetivou-se, com o presente trabalho, refletir sobre o exercício da participação e entender o sentido de controle social no campo pesquisado. É também nossa intenção contribuir para o reconhecimento desses conselhos como dispositivos que possibilitam a reinvenção do cotidiano - da rua, da comunidade, do bairro -, com ações coletivas e o encontro entre os sujeitos participantes, alterando posturas historicamente cristalizadas e concretizando a vontade popular por uma saúde mais próxima, integral e efetiva.

\section{APROXIMAÇÕES TEÓRICAS}

A participação, além de ser um meio para a solução de problemas cotidianos, é, sobretudo, “[...] uma necessidade fundamental do ser humano, como a comida, o sono e a saúde" (BORDENAVE, 1983, p. 16). Nas palavras do autor, é pela participação que os seres humanos se realizam e desenvolvem seu potencial pleno. É também por meio dela que realizam e fazem coisas e se afirmam como sujeitos no mundo.

A participação não pode ser considerada um fenômeno novo. Diferentes formas, com diversos objetivos, já eram experimentadas em outros tempos; assim, podem-se 
exemplificar experiências de conselhos em outras épocas, apesar de nem sempre terem a visibilidade apresentada na atualidade. Estes conselhos, conforme Silva (2000) eram:

[...] imbuídos de objetivos diferentes dos atuais, isto é, integrados à luta pela emancipação política, social, cultural e econômica, tais como os comitês da comuna de Paris, os sovietes russos, os conselhos de fábrica da Itália, os conselhos operários da Alemanha [...]. (ibid., p. 28)

Segundo a autora, embora não apontassem apenas nesta direção, apareceram também como mecanismos para promover a integração dos diferentes segmentos ao aparato do Estado, em cuja estrutura e em comum acordo poderiam atuar na execução de políticas ou, até, na busca de soluções para o enfrentamento das questões sociais.

Nessa direção, Gohn (apud SILVA, 2000) distingue os conselhos em populares e comunitários.

Os conselhos populares tiveram sua origem nos movimentos sociais e objetivaram a negociação de suas lutas com o poder público; para sua existência, a organização e a participação popular eram condições fundamentais.

Bastante diferentes, os conselhos comunitários foram criados pelo próprio poder público, via decreto, para que mediassem sua relação com os diferentes movimentos sociais. Estas instituições, caracterizadas como populares, tinham por função apaziguar as relações e cooptar as lideranças, apoiando, fundamentalmente, as ideias dos governantes.

A existência dos conselhos no Brasil, data do final da década de 1960 e mostra que, de fato, não são fenômenos novos, embora seu caráter consultivo e suas atribuições sejam diferentes das que apresentam os conselhos de políticas sociais do cenário atual.

Vianna, Cabral e Cavalcanti (2009) chamam a atenção para algumas mudanças promovidas por vários governos nas estruturas burocráticas estatais na década de 70, pelas quais foram delegadas funções à sociedade e ao mercado, e se implantaram mecanismos de participação destinados a desburocratizar e a "domesticar" os processos decisórios. Nisso, segundo as mesmas autoras, alguns formuladores de políticas de diferentes posições ideológicas e formuladores de teorias, adeptos de diferentes segmentos das Ciências Sociais, identificam que "um aparente consenso se constitui em torno do tema participação, cada vez mais societalizado e cada vez menos politizado" (VIANNA, CABRAL \& CAVALCANTI, 2009, p. 237).

A participação social, como elemento estruturante do sistema de saúde em suas diferentes esferas, esteve presente desde início da proposta do Movimento da Reforma 
Sanitária, que, já nos anos 70, compreendia como indissociáveis as lutas contra a Ditadura Militar, pela democratização do poder público e pela garantia da saúde como direito do cidadão e dever do Estado (ESCOREL, MOREIRA, 2008).

A viabilização da participação da sociedade civil organizada no processo de gestão das políticas públicas brasileiras somente foi possível por meio de conquistas que culminaram com sua inclusão no texto constitucional de 1988. Na conjuntura da década de 1980, em meio à crise social e aos esforços democratizadores, a Constituição de 1988 definiu instrumentos para a participação da sociedade civil no controle da gestão das políticas públicas pela instituição de conselhos cujos integrantes representariam seus diferentes segmentos na implementação e no controle das políticas públicas (RAICHELIS, 1998).

Na política de saúde, a participação social e comunitária garantida pela Lei n. 8.142 e a de n. 8.080, ambas de 1990, que regulamentam a participação da comunidade na gestão do Sistema Único de Saúde - SUS - através de conferências e conselhos nas três esferas - nacional, estadual e municipal -, instituindo um sistema de controle social.

Entende-se por controle social a possibilidade de participação na gestão do sistema, no caso, de saúde, por parte de toda a sociedade, em espaços como os acima referidos (conselhos e conferências). É a capacidade que a sociedade tem de influenciar o planejamento e a gestão da coisa pública, alargando as possibilidades de construção de uma esfera verdadeiramente pública (CORREIA, 2000).

Raichelis (2000) contribui com este entendimento ao afirmar que o controle social implica o acesso aos processos que informam decisões da sociedade política, que devem viabilizar a participação da sociedade civil na formulação e revisão das regras, segundo critérios pactuados, que conduzem as negociações e arbitragens sobre os interesses em jogo, além de fiscalizar aquelas decisões.

A partir de uma investigação exploratória em periódicos da lista Qualis ${ }^{3}$ do Portal Capes, realizada por Vianna, Cabral e Cavalcanti (2009), ao mapear a produção acadêmica sobre o tema participação social em saúde de um modo geral, os autores das 99 publicações mapeadas caracterizam a participação como "[...] a capacidade de os indivíduos influenciarem as decisões políticas que dizem respeito à sociedade em que vivem”. A participação, neste sentido, é relacionada como algo positivo e que estimula a

\footnotetext{
${ }^{3}$ Qualis é o resultado da classificação feita pela Capes dos veículos utilizados pelos programas de pósgraduação na divulgação da produção intelectual de seus docentes e alunos.

Serv. Soc. \& Saúde, Campinas, SP v. 11, n. 2 (14) p. 245-268 jul./dez. 2012 ISSN 1676-6806
} 
ampliação da cidadania dos sujeitos participantes. As autoras ainda identificam um significativo número de estudos que entendem a atuação nos espaços de participação como um elemento que contribui para a "qualificação da gestão, a maior equidade nas distribuições de recursos, o acesso aos serviços e a melhora da atenção em saúde" (2009, p. 239-240).

Além disso, a participação social dos sujeitos que atuam nos conselhos e conferências representa uma conquista na construção da cidadania. Mesmo que por si sós não garantam uma participação plena e efetiva, a idealizada pelo próprio movimento da Reforma Sanitária constitui um processo político-pedagógico de fortalecimento da sociedade civil, no qual os sujeitos sociais se transformam em sujeitos políticos hábeis e potentes, capazes de induzir intervenções positivas na implementação do SUS (VIANNA, CABRAL e CAVALCANTI, 2009).

Para Péret (2001), mesmo com canais de participação já instituídos, é necessário que os próprios profissionais da saúde, como potencializadores dessas ações, rompam com o ranço das antigas políticas que excluíam os cidadãos dos serviços públicos de saúde, ampliando o conceito de participação social também em sua magnitude, não se limitando apenas aos canais institucionais. O autor refere-se a uma participação social voltada a todos e não somente aos sujeitos afinados com os costumeiros jargões institucionais.

Para Carvalho (1998):

Os conselhos são instâncias de formação de políticas que gozam de alto conceito de respeitabilidade enquanto espaços transparentes e comprometidos com o interesse público, espaços que tornam a política mais pública, pelo menos aqueles em que há participação de grupos sociais organizados e democráticos (ibid., p. 34).

Ao identificar o espaço dos conselhos como mecanismo de representação e de discussão de políticas, Campos e Maciel (1997, p. 149) afirmam que eles se constituem no “[...] canal de participação legalmente constituído para o exercício da gestão democrática". Os autores reconhecem que os conselhos paritários são espaços privilegiados para o exercício político e de sujeitos políticos. Estes conselhos, paritários e deliberativos, são iniciativas que possibilitam, mesmo em uma esfera restrita, estabelecer novos fóruns de participação e novas formas de relacionamento entre o Estado e a sociedade civil.

Outro mecanismo, encontrado no cenário de muitos municípios, são os conselhos locais de saúde, que, de acordo com Santiago \& Lacerda (2007, p. 200) são Serv. Soc. \& Saúde, Campinas, SP v. 11, n. 2 (14) p. 245-268 jul./dez. 2012 ISSN 1676-6806 
“[...] um espaço potencializador da criatividade dos usuários na proposição e elaboração da política local de saúde". De acordo com os autores, tais conselhos foram idealizados para permitir a participação da comunidade, juntamente com os profissionais, na discussão de questões de seu interesse, bem como na elaboração de propostas a serem levadas a instâncias decisórias para definição, a exemplo dos conselhos e conferências municipais de saúde. Trata-se, portanto, de um espaço inovador, já que são compostos pelos sujeitos que vivenciam o cotidiano da comunidade e da saúde local. Segundo os autores, esses conselhos locais, embora não previstos na forma da Lei federal $\mathrm{n}$. 8.142/90, podem ser traduzidos como possibilidade de ampliação da participação comunitária na fiscalização, proposição e execução da política de saúde.

O mesmo reconhecimento é apontado por Bravo, quando afirma que o conselho local de saúde é uma "entidade não instituída jurídica e legalmente, mas que possibilita a participação da comunidade na elaboração de propostas para a política de saúde em sua localidade". Consiste ainda na "articulação dos usuários e dos trabalhadores de saúde, com a finalidade de estabelecer relação entre os conselheiros e a base" (2001, p. 133).

Em estudo realizado na cidade de São Paulo, Cohn, Elias e Jacobi (1993) confirmam que os conselhos de saúde são catalizadores do processo de educação para a cidadania e de promoção da consciência sanitária, pelo qual os representantes dos usuários são levados a complexificar as questões de saúde com seu envolvimento e participação. Participação esta articulada à prática educativa, pela qual os diferentes segmentos do conselho aprendem a reconhecer suas diferenças, aquilo que os move, suas necessidades e desejos. Neste sentido, segundo Barros (1998, p.19), os conselhos podem ser considerados como possibilidade de socialização de informações que estimulam os sujeitos na defesa da saúde como direito social, sendo reconhecidos como “espaço de disseminação de informações que alimentam a luta pela preservação do direito universal à saúde".

Os conselhos locais de saúde contribuem com a concretização de espaços de participação popular e comunitária, nos quais os profissionais da Estratégia de Saúde da Família - ESF - e comunidade podem discutir sobre questões de interesse comum, elaborando e levantando propostas para as instâncias decisórias, como conferências e conselhos municipais (SANTIAGO, LACERDA, 2007). 


\section{CONSELHO MUNICIPAL E CONSELHOS LOCAIS DE SAÚDE DE FLORIANÓPOLIS: UMA BREVE INCURSÃO}

O Conselho Municipal de Saúde de Florianópolis é um órgão de deliberação coletiva e de caráter permanente. Foi criado pela Lei municipal $n^{0}$. 3.291, de 1/11/19894, e seu regimento interno foi instituído no ano de 1993. O conselho realiza reuniões ordinárias mensais e, quando necessário, reuniões extraordinárias. Sua estrutura ainda possibilita a criação de câmaras técnicas, com o objetivo de tratar de assuntos específicos e assessorar o plenário do conselho em matérias cuja especificidade, importância ou urgência o justifiquem, ou atendendo a determinações legais, através de grupos de trabalho ou comissões internas e intersetoriais (PMS, 2007).

Criados a partir de 2000 em Florianópolis, os conselhos locais de saúde são vistos como estratégias de mobilização social (PMS, 2007). O regimento interno do Conselho Municipal de Saúde de Florianópolis apresenta, no título VII, nos artigos 31 e 32, questões sobre sua relação com os conselhos locais. O documento os caracteriza como órgãos consultivos e propositivos do SUS, que encaminham suas demandas ao Conselho Municipal ${ }^{5}$.

Este, além do regimento interno, emitiu a resolução $n^{0} 010 / C M S / 2008$, que define os conselhos locais de saúde como:

[...] órgão consultivo do Sistema Único de Saúde - SUS -, na área de abrangência da unidade local de saúde, relacionando-se diretamente à hierarquia do Conselho Municipal de Saúde, atuando com atenção especialmente aos níveis de planejamento local, avaliação da execução, e controle social das ações e serviços de saúde ou correlacionadas à saúde, colaborando na definição de prioridades e estabelecimento de metas a serem cumpridas na área de abrangência da unidade de saúde.

Conforme esta resolução, a composição desses conselhos deve respeitar a Lei 8.142/90, na qual as representações devem ser paritárias, constituindo-se de 50\% de representantes usuários e de 50\% de representantes da unidade local de saúde, entre profissionais ou trabalhadores da saúde e prestadores de serviços de interesse da saúde.

Nesse segmento, Florianópolis é dividida em cinco distritos sanitários: Norte, Sul, Leste, Centro e Continente. Até o ano de 2007, havia cerca de 15 conselhos locais de saúde (PMS, 2007); já em abril de 2010 havia 24, distribuídos nos 5 distritos

\footnotetext{
${ }^{4}$ A Lei n 3291/1989 cria e define atribuições ao Conselho Municipal de Saúde de Florianópolis.

${ }^{5}$ Regimento Interno do Conselho Municipal de Saúde (CMS) de Florianópolis/SC. 2009.

Serv. Soc. \& Saúde, Campinas, SP v. 11, n. 2 (14) p. 245-268 jul./dez. 2012 ISSN 1676-6806
} 
sanitários: 2 no Distrito Centro, 4 no Distrito Norte, 9 no Distrito Sul, 5 no Distrito Leste e 4 no Distrito Continente, cinco deles em formação/reestruturação, e mais 20 a constituir 6 .

\section{O CAMPO DE PESQUISA: DOIS CONSELHOS LOCAIS DE SAÚDE NO DISTRITO CONTINENTE}

O Distrito Continente, localizado na região continental da Ilha de Florianópolis, tinha cerca de 104.846 habitantes em 2008 (IBGE), numa área de 12,1 km². A região é considerada bastante populosa, visto abranger apenas 2,77\% do território do município, mas cerca de $26 \%$ da população da cidade. É a porção continental da capital que faz o único limite terrestre com outro município, a oeste, o município de São José. Pela confluência de tais aglomerados urbanos, muitas vezes seus limites territoriais passam despercebidos.

A região do continente se diferencia da ilha em alguns aspectos. Um, é o de não ter como atividade principal o turismo, bastante forte na ilha. As principais atividades econômicas desenvolvidas na região são as de comércio e serviço, nas quais o bairro Estreito se destaca.

Segundo a Secretaria de Saúde de Florianópolis, o Distrito Continente possui cerca de 21 áreas de interesse social, ${ }^{7}$ totalizando uma população de 21.017 pessoas, o que corresponde a 34,20\% da população do município residente em áreas de interesse social $^{8}$. O continente possui 11 unidades básicas de saúde: Abraão, Balneário do Estreito, Capoeiras, Coloninha, Continente, Estreito, Jardim Atlântico, Monte Cristo, Morro da Caixa, Sapé e Vila Aparecida. Apenas quatro destas possuem conselhos locais de saúde formados.

\footnotetext{
${ }^{6}$ Informação obtida através de documento do Conselho Municipal de Saúde de Florianópolis, datado de 19/4/2010.

${ }^{7}$ As áreas de interesse social, ou áreas de risco e/ou áreas carentes, são regiões classificadas a partir de alguns critérios como: 1) renda familiar até três salários mínimos e predomínio de renda per capita abaixo da linha de pobreza (R\$ 180,00/ mês - IPEA); 2) unidades habitacionais precárias, isoladas ou em agrupamento, apresentando uma distribuição espacial caótica; 3) unidades habitacionais precárias, localizadas em áreas de risco: a) encostas de morro suscetíveis a desmoronamentos; b) áreas de preservação permanente, áreas verdes, nascentes de rios e córregos; c) áreas de mangues e dunas; d) áreas próximas a leitos de rios, de córregos, canais e praias, suscetíveis a inundação; 4) posse irregular em áreas públicas e/ou privadas; 5) áreas desprovidas parcial ou totalmente de infraestrutura (água tratada, rede elétrica, sistema de esgoto sanitário, rede pluvial, pavimentação, coleta de lixo); 6) áreas desprovidas parcial ou totalmente de serviços e equipamentos públicos (creches, escolas, postos de saúde, posto policial etc.) (SMS, SH - PMF, 2006).

${ }^{8}$ Fonte: Diagnóstico das áreas de interesse social. Secretaria Municipal de Habitação, trabalho e desenvolvimento social - Prefeitura Municipal de Florianópolis/SC. 2006.

Serv. Soc. \& Saúde, Campinas, SP v. 11, n. 2 (14) p. 245-268 jul./dez. 2012 ISSN 1676-6806
} 


\section{TRAÇADO METODOLÓGICO}

Nesta pesquisa, privilegiou-se uma abordagem qualitativa, de caráter exploratório-descritivo. A pesquisa qualitativa trabalha com o universo de significados, motivos, aspirações, crenças, valores e atitudes, o que, de acordo com Minayo et al. (1994), responde a um espaço mais profundo das relações, dos processos e dos diversos fenômenos sociais. Embora existam diversas abordagens qualitativas, estas apresentam um propósito comum, o de analisar os significados atribuídos pelos sujeitos aos fatos, relações e práticas, isto é, compreendem tanto as interpretações quanto as práticas dos sujeitos (BOSI; MERCADO, 2007).

Este estudo, exploratório-descritivo, teve como campo de pesquisa dois conselhos locais de saúde do distrito, buscando discutir, sob a ótica dos conselheiros, como se dá a participação e o que entendem por controle social.

A ferramenta principal da coleta de dados foi uma entrevista semiestruturada, que se materializa na interação social entre entrevistador e entrevistado (GIL, 1994). As entrevistas foram gravadas em áudio e transcritas em sua totalidade. Após a transcrição, a análise do material foi realizada através de um tratamento qualitativo, pelo método de análise de conteúdo.

De acordo com Bardin, a análise de conteúdo pode ser entendida como:

Um conjunto de técnicas de análise das comunicações visando obter, por procedimentos sistemáticos e objetivos de descrição do conteúdo das mensagens, indicadores (quantitativos ou não) que permitam a inferência de conhecimentos relativos às condições de produção/recepção [...] destas mensagens (1977, p. 42).

Tudo o que é dito, falado e transformado em comunicação é passível de análises. Pode, assim como qualquer comunicação, ser submetido à análise de conteúdo. Isto significa que qualquer transporte de significações de um emissor para um receptor poderia ser escrito e decifrado pelas técnicas de análise de conteúdo (BARDIN, 1977).

Para a discussão dos dados finais, referenciamos autores e autoras - Raichelis (2000), Correia (2000) e Cotta, Cazal e Rodrigues (2009) - para os quais controle social é visto como possibilidade de participação na gestão do sistema de saúde, capacidade de influenciar na escolha das prioridades das ações em saúde em determinado território e fiscalização das ações e acesso às decisões. Já como participação, ancorados nas ideias de Bordenave (1983), compreendem o movimento de envolver-se com determinada questão. No caso da saúde da população, envolvimento pressupõe fazer algo, tomar e ter 
parte em algo. Portanto, a participação implica estar junto, ser sujeito e usufruir de determinado bem.

Considerando que toda pesquisa tem seu limite e que apreende certo dado em determinado momento, podendo este se movimentar ou sofrer alterações substanciais no tempo, Geertz (1989) nos previne sobre o perigo de considerar que os estudos e pesquisas sejam uma fotografia em miniatura da realidade, pois, mesmo que representem um conhecimento apreendido e legítimo em determinado tempo histórico, não conseguiremos capturar todo o conjunto de relações presentes na realidade. Portanto, esta pesquisa, embora traga questões importantes para reflexão sobre os espaços dos conselhos locais em Florianópolis, não pretendeu identificar a realidade do município, mas apenas apresentar e discutir alguns dados de realidade para que se possam aprofundar novas reflexões sobre o tema proposto.

Os conselhos participantes desta pesquisa têm mais de dois anos de formação, e enfrentam, frequentemente, momentos de "altas e baixas". No presente trabalho, desses dois conselhos participaram nove conselheiros, dos quais, cinco usuários e quatro profissionais de saúde.

A pesquisa foi iniciada logo após receber a aprovação do Comitê de Ética em Pesquisa com Seres Humanos (CEPSH) da Universidade Federal de Santa Catarina UFSC -, processo $n^{\circ} 601$, folha de rosto: 317447.

Apresentação dos dados e discussão dos resultados

\section{PERFIL DOS CONSELHEIROS}

A idade dos nove conselheiros variava, no momento da pesquisa, entre 36 e 71 anos, apresentando uma média de 49 anos. Dos nove conselheiros, quatro eram homens e cinco, mulheres. Dos nove, cinco eram usuários (as) e quatro, profissionais de saúde trabalhadores e gestores. Com relação ao grau de escolaridade: dois conselheiros/as tinham apenas o primeiro grau completo (22\%); um (1) tinha o segundo grau incompleto (11\%); três, o segundo grau completo (33\%); um (1), o terceiro grau completo (11\%) e dois, o curso de pós-graduação lato sensu (22\%). O tempo médio de participação dos conselheiros no conselho local era de uma gestão.

Estes dados mostram que os conselheiros de saúde deste estudo apresentam bom nível de escolaridade; pelo menos 66\% concluíram o segundo grau. Foi possível 
perceber também a ausência de jovens, ou menores de 30 anos, o que talvez indique que o espaço dos conselhos não tem sido por eles frequentado.

\section{COMO ENTENDEM O CONSELHO LOCAL DE SAÚDE}

Dos conselheiros pesquisados, uma boa parcela, cerca de 30\%, acredita que o espaço do conselho local é uma instância de resolução de problemas do setor de saúde local, razão pela qual seriam corresponsáveis pela melhoria das condições de saúde da comunidade - território de responsabilidade da unidade de saúde e do conselho locais. As falas mostram o que pensam sobre o conselho local, ou sobre o que veem acontecer cotidianamente nesses espaços, muitas vezes criando imagens não muito positivas sobre eles:

- O conselho local tem que ser, de como se resolver o problema, como se fosse um ente mais administrativo... Então ele tem essa função de segurar o posto de saúde de uma certa maneira dos problemas que tem [...]

Pra resolver os problemas da saúde, né?... os problemas local... pra isso é local de saúde... (1)

Além da imagem cristalizada que se cria, falar que o conselho local é um espaço “pra resolver problemas" pode significar, em sua visão, que se trata puramente de um órgão administrativo, e não de um espaço político, no qual, através de discussões e negociações, se encaminham as decisões compartilhadas pelos diversos atores presentes - usuários, profissionais de saúde e gestores - para a melhoria de saúde da população, o que comportaria mudanças e, de consequência, o fortalecimento do SUS, como aparece nas declarações de outros/as conselheiros/as:

- Eu acho que o conselho é para as melhorias da comunidade, pra conseguir algo a mais... A comunidade com os funcionários. (2)

- Bom, o conselho é um grupo de pessoas que fazem parte dele, pessoas da comunidade, trabalhadores e o próprio governo... então esse grupo de pessoas se reúnem para decidir mudanças, melhorias... (3)

- Eu entendo conselho local de saúde em que as pessoas possam quase ser um representante da comunidade... (5)

- O conselho local de saúde é pra contribuir pro melhoramento do SUS... (4)

O conselho local é reconhecidamente um local de encontro, espaço onde a população pode expressar os problemas que percebe no sistema de saúde, localizando demandas para possíveis ações da unidade básica, ou mesmo do Conselho Municipal. 
Embora o conselho local seja caracterizado por um/a conselheiro/a como um espaço restrito, ele possibilita que as decisões tomadas na esfera local sejam mais coerentes e mais bem embasadas em conhecimentos do território se passadas sob seu crivo e pela criatividade dos usuários do sistema, aqueles que, de diferentes "lugares", com outros "óculos", indicam distintas possibilidades na escolha de soluções para determinadas questões que sentem ou vivenciam no cotidiano dos serviços de saúde. Assim:

- O conselho local é muito restrito, por que é mais um órgão fiscalizador, por que somos subordinados ao conselho municipal... o conselho local existe mais para ouvir o morador, o morador procura o conselho local e nessas reuniões que são realizadas mensalmente a gente discute os problemas do posto e os problemas enfrentados pelos moradores...(7)

- Então ele tem essa função... de ter a criatividade pra resolver alguns problemas que a própria administração não vai conseguir resolver se não consultar os usuários, então ele é muito conciliador; não existe uma briga entre os profissionais e os usuários, e sim como nós podemos resolver os nossos problemas? Então ele tem essa função conciliadora. (9)

Após reconhecer que é um lugar de escuta, e muitas vezes apenas de catarse, é encarado também como possibilidade de direcionamento de algumas ações em saúde, abrindo caminhos para movimentos de reivindicação em outros espaços, como no Conselho Municipal de Saúde, ou até mesmo com os gestores municipais. O conselho local, algumas vezes, como apresentado em depoimentos, se afasta da instância local e se aproxima de proposições que dizem respeito a questões de ordem mais distrital ou municipal:

- [...] não somos órgãos executores; o conselho local não tem como executar; ele tem apenas como reivindicar. A única solução, o único poder que tem é localizar e depois reivindicar. (8)

- [...]então o conselho local é um começo de instrumento que pode levar isso ao conselho municipal... é um instrumento de política muito forte... então o nosso trabalho é descobrir o problema, localizar ele, e reivindicar, lutar através do próprio conselho municipal e através de reuniões que a gente faz com a coordenação do continente... (9)

- Só a reunião que a gente teve com o secretário, eu acho que ali tinha um representante do conselho municipal... na sala do secretário... então a gente pedia para ampliar o nosso laboratório e que os exames fossem mais perto possível... essas daí foram algumas coisas que a gente achou que foi atendida. Dentro do possível, foi atendida. (5)

O conselho local de saúde é um lugar múltiplo, de muitas possibilidades, constituído pelas relações entre os diferentes segmentos - usuários, profissionais de Serv. Soc. \& Saúde, Campinas, SP v. 11, n. 2 (14) p. 245-268 jul./dez. 2012 ISSN 1676-6806 
saúde e gestores locais -; está sempre em mudança, já que depende dos atores dispostos a "contracenar". É visto como local para reconhecer e discutir os problemas locais relacionados à saúde, bem como a outros fatores que se relacionam a ela. É espaço de forças e interesses políticos diferenciados, mesmo que não muito aparentes nos discursos e ações. É um dos elos entre a unidade de saúde e a população do território, sendo um canal de comunicação institucionalizado. É também um espaço pouco conhecido e aproveitado pela própria comunidade, o que veremos na discussão sobre a participação nos conselhos.

\section{O QUE ENTENDEM E FALAM SOBRE CONTROLE SOCIAL}

Ao ouvir os conselheiros, percebeu-se que poucos sabiam efetivamente da existência e do significado do termo "controle social", ou afirmavam desconhecê-lo. Alguns confundiam o termo com diferentes temas, como controle de natalidade, áreas de pobreza, controle do Estado sobre a população e controle da sociedade. Nas falas a seguir, ilustram-se o desconhecimento e a mistura de conceitos:

- Nunca ouvi falar, eu preciso ouvir um pouco mais sobre isso... (1)

- Eu acho que na nossa região aqui é uma região de classe média, né? O controle social pra mim é onde tem assim, um, assim pessoas que precisam mais, né? Que tenham mais necessidade... (2)

- Controle social... não... Tá um negócio assim meio fechado, controle social parece assim que vai existir um controle na população... até quero que você me esclareça. (5)

- Eu acho que controle social foi feito na marra, por que com esse problema da Aids, o pessoal tá transando com camisinha e tá fazendo controle social na base da doença...então o controle foi feito pela doença e não pelo plano governamental. (6)

Outros se aproximam do conceito de controle social quando afirmam que é algo que pode contribuir para melhora dos problemas da sociedade, que só pode ser exercido se as pessoas conhecem os problemas e dificuldades na área da saúde, e também o reconhecem como algo que se institui a partir do exercício da democracia ou, ainda, quando descrevem suas ações de acompanhamento e participação nas atividades com a unidade de saúde.

- Controle social é a participação da comunidade nesse processo... a gente pode informar onde tão esses problemas ou essas dificuldades... eu acho que informando a comunidade disso elas passam a ter dados para lutar e solicitar o que elas tão precisando. (3) 
- Controle social é para melhorar a sociedade, os problemas que tem na sociedade, seria pra melhorar... (4)

- Controle social hoje é você poder controlar as políticas públicas de certa forma que não tenha nenhum problema administrativo... primeiro eu consulto todo o grupo e depois eu vejo o que eles querem... aí eu começo a fazer controle social através da democracia, a nível de finanças é muito importante... (9)

$\mathrm{Na}$ leitura atenta dos enunciados captados nas entrevistas, percebeu-se que muitos dos conselheiros realizam ações que contribuem para o exercício do controle social local sobre as ações da Unidade Básica de Saúde, mesmo sem saber que aquilo que faziam modificava o redirecionamento das ações no território e contribuía para isso, aproximando-se da gestão das ações e do exercício do controle social.

Buscando contribuir com a melhora de saúde da população do bairro e fazer acontecer o controle social, os conselheiros o veem como possibilidade de acesso às decisões do espaço do conselho municipal, muitas vezes utilizado como estratégia para chamar a atenção para problemas locais e dar visibilidade, de certa forma, a um espaço mais amplo, que é o conselho municipal. Assim os conselheiros expressam:

- [...] por que o que não é resolvido no conselho local aí o municipal entra em ação, né? (4)

- Acho que algumas dessas proposições que a gente fazia aqui eram ouvidas no conselho municipal, sim. Tanto é que a gente teve, como a gente tem, o segundo turno, né? (3)

Abre-se a possibilidade da criação de uma esfera de discussão de prioridades entre conselho local, conselho municipal e gestão municipal, o que Raichelis chama de esfera pública ${ }^{9}$. O conselho local se utiliza de vários recursos e estratégias para garantir que algumas de suas reivindicações sejam discutidas e cumpridas, quando não pelo espaço que desbravam no conselho municipal para ter vez à voz, procuram outros órgãos executores, como aparece a seguir:

- [...] tava tendo um problema grave marcação de consulta... então através do conselho local de saúde a gente chamou a ... (pessoa responsável por um setor no Distrito Sanitário Continente); foi feita uma normativa que teria que atender " $\mathrm{x}$ " dias e ampliar número de médicos e tá dando resultado. Então, foi levado ao local correto a reivindicação e a reivindicação foi atendida. (8)

\footnotetext{
${ }^{9}$ Parte integrante do processo de democratização, para Habermas (1984), Arendt (1991) e Telles (1990) (apud RAICHELIS, 2000, p. 64), a esfera pública constitui um espaço essencialmente político, de aparecimento e visibilidade, onde tudo o que vem a público pode ser visto e ouvido por todos. Serv. Soc. \& Saúde, Campinas, SP v. 11, n. 2 (14) p. 245-268 jul./dez. 2012 ISSN 1676-6806
} 
- Todo posto de saúde, todo conselho local de saúde não importa de qual região que tem algum problema, nós usuários não podemos falar na reunião do conselho (referindo-se ao conselho municipal de saúde). Isso é uma falha. Nós usuários abrimos a fala pra ele, nós podemos fazer isso, desde que passe a palavra pra pessoa que tenha o problema e a pessoa se expressa por aí. Então virou uma prática comum, eu acho que são cinco ou seis conselheiros que estão disponíveis a fazer isso... esses fazem uma construção pra que as unidades tenham voz e aí cobra, inclusive está prestes a sair uma comissão pra tratar só do conselho local... (9)

É dessa forma, muitas vezes diferenciada, criativa e negociada, que os conselheiros locais conseguem colocar seus desejos coletivos em evidência. Numa esfera aparentemente mais restrita - o espaço local -, introduzem novas possibilidades do exercício do controle social, principalmente nas proposições de funcionamento da unidade básica de saúde e de seus serviços, não tendo nessa instância acesso a decisões de ordem financeira.

O controle social daria um salto em qualidade e intensidade se provássemos da democracia participativa, que, no olhar de Bordenave "[...]promove a subida da população a níveis cada vez mais elevados de participação decisória, acabando com a divisão de funções entre os que planejam e decidem lá em cima e os que executam e sofrem as consequências cá embaixo" (1983, p. 34).

\section{A PARTICIPAÇÃO NO CONSELHO LOCAL}

Os conselheiros locais de saúde (os sujeitos aqui pesquisados) - moradores do território, profissionais e gestores de saúde -, apresentam histórias de participação e envolvimento em movimentos sociais e organizações políticas bem diferenciadas. No período em que a pesquisa foi realizada, nos meses de maio e junho de 2010, seis (66\%) dos nove conselheiros não participavam de outro espaço político além do conselho local de saúde; apenas três, cerca de 33\%, estavam envolvidos com outras lutas e movimentos, dentre os quais se destacavam as associações de moradores de bairro, além de entidades conhecidas na cidade e no estado, como a União Florianopolitana de Entidades Comunitárias - UFECO - e Federação de Associações do moradores do estado de Santa Catarina - FAMESC. Dos que não participavam de outros espaços além do conselho local de saúde, apenas um relatou ter participado, no passado, de um conselho municipal de saúde de outro município. 
Quando indagados sobre como se deu sua entrada no conselho local, quatro dos nove conselheiros, cerca de 44\%, afirmaram que tinham a obrigação de participar porque haviam feito parte de seu trabalho nessa área, e que não teriam como não participar, não tendo, portanto, outra escolha. Os outros cinco, cerca de $55 \%$ dos pesquisados, afirmaram que sua participação se deu por influência e/ou convite de amigos que haviam sido conselheiros locais anteriores, ou mesmo por meio de convites do Conselho Municipal e/ou da Associação de Moradores do Bairro. Vejamos esses dados expressos em falas:

- Na real foi pra montar mesmo, pra ter participante... Até o (a) coordenador (a) escolheu, e a gente foi até o local... e a gente foi escolhido para poder participar. (2)

- Tem a obrigação, mas assim, eu acredito no SUS, eu acredito que a participação popular é imprescindível pra tá acontecendo mudanças... (3)

- Tem que todos participar por que é horário de trabalho... e sendo horário de trabalho a gente vai. (4)

Com conteúdo de fala diferenciado, outros conselheiros atribuem significados à sua participação:

- Ahn, por que primeiro eu uso muito e não tenho nenhum outro plano de saúde e outra... eu sou muito ligada a ser direita, a exercer a cidadania... pra cobrança daquilo que a gente tem direito. (5)

- [...] através da associação de moradores eu comecei a participar, mas como eu já fui agente comunitário/a de saúde... então eu sempre tive contato com a comunidade, sempre fui um elo entre a comunidade e o posto de saúde. (8)

- Por que não existia conselho local no posto de saúde... como ainda em vários não existe e como conselheiro municipal de saúde, nós usuários começamos a incentivar através da associação de moradores para que eles fossem os atores principais nesse conselho. Eu também fazia parte da associação de moradores... (9)

As narrativas falam por si. Os conselheiros têm histórias diferentes. Por influência dessa história, participam do conselho local com mais intensidade e desejo; outros, desejando ou não, têm por obrigação participar. Parece-nos que é grande a presença de atores sociais sem muita experiência em participação. De acordo com os depoimentos anteriores, muitos não participavam de nenhum outro espaço de discussão política e social, espaços que os enriqueceriam e fortaleceriam para se fazer presentes no conselho de forma diferenciada, construindo significados para a sua prática para Serv. Soc. \& Saúde, Campinas, SP v. 11, n. 2 (14) p. 245-268 jul./dez. 2012 ISSN 1676-6806 
além dos limites regimentais do conselho, embora isso não desmereça os que se limitam a participar do conselho local com sua energia e ideias, mesmo em meio à semana de trabalho e/ou de outras atividades cotidianas. Segundo Bordenave (1983), mesmo sendo a participação uma necessidade básica, as pessoas não nascem sabendo participar; é uma habilidade que se aprende e se aperfeiçoa durante a vida.

Considerando as diferentes formas de participar dos conselheiros, pode-se afirmar, com base nos conselhos locais pesquisados, serem duas as principais maneiras. Uma diz respeito à participação voluntária. Nesta modalidade, os sujeitos optam por participar do grupo ou não, tendo autonomia para estabelecer seus objetivos. A outra aproxima-se do que Bordevane (1983) chama de participação dirigida, pois sofre influência de sujeitos externos, com a finalidade de atingir objetivos previamente estabelecidos.

As reuniões dos dois conselhos pesquisados são realizadas mensalmente; não contam com uma presença expressiva de pessoas da comunidade. Durante todas as entrevistas, sem exceção, os conselheiros apontavam a falta de participação e o pouco envolvimento da comunidade como um dos seus principais problemas, o que, na visão de um deles, reduz o poder de ação do conselho:

- A gente fica de mãos atadas. Como é que vamos reclamar, reivindicar melhorias se o morador não participa? Ele é a parte interessada, o maior interessado é o morador. (7)

- [...] eles têm o espaço pra eles reivindicar, eles não aproveitam, ali é o momento e eles não se atentam, né? ... a gente gostaria que a comunidade tivesse uma representação maior nessas reuniões, era muito bom. (4)

A não-participação e o não-envolvimento da comunidade nas reuniões e, consequentemente, nas ações dos dois conselhos locais é algo que angustia e desestimula o trabalho de muitos conselheiros. Alguns acreditam que as pessoas em geral não participam porque não conhecem o conselho, não sabem para que serve e, consequentemente, não o veem como algo capaz de promover mudanças na área da saúde. As narrativas demonstram, sob a ótica deles, um dos motivos da não-participação da população:

- [...] as pessoas não dão muita importância para o que é o conselho local de saúde, mas também talvez não saibam o que é, qual o papel, a importância que tem..." (3)

- Às vezes não são usados pelos usuários por não saber o poder que tem o conselho. (9) 
Além do pouco conhecimento do conselho local no bairro, ou mesmo seu nãoreconhecimento como espaço legítimo que pode gerar mudanças na saúde local, fatores de ordem cultural e social, construídos na história de nossa sociedade e, portanto, na história de vida de cada um, influem no sentido de que as pessoas deixam de ser protagonistas de sua própria história e da história de saúde da sua comunidade.

- Eu acho que hoje as pessoas estão envolvidas com uma série de coisas... e acaba a atenção delas sendo desviada por outras coisas, sabe, o descrédito do governo tem muito haver sim, pra que que eu vou lá se não acontece nada, não é bem assim... (3)

- [...] a gente escuta muita ladainha... a gente vê assim que o pessoal tá meio desacreditado, revoltado e deixa o negócio correr, pra que estar mexendo lá se ninguém vai resolver nada... vocês vão mexer numa cachopa de marimbondos e vão ser mordido e não vão resolver nada. (6)

- Eu acho que as pessoas não participam por comodidade e por experiências passadas, experiências passadas de não ver resultados. Que as pessoas botaram isso na cabeça, que não adianta mais... por que é perda de tempo. (8)

Os/as conselheiros/as nos chamam a atenção para algo que está por se construir na história de nosso país, hoje considerado um estado democrático: o exercício da cidadania e da participação social, embora já instituídas em leis, como declarado nas leis 8.080 e 8.142, de 1990, que inauguraram de forma mais alicerçada a participação da sociedade no Sistema Único de Saúde. Talvez seja pretensioso demais afirmar que a participação faz parte do cotidiano das pessoas, das comunidades. Para Bordenave “[...] democracia não é apenas um método de governo... é um estado de espírito e um modo de relacionamento entre as pessoas. Democracia, portanto, é um estado de participação" (1983, p. 8).

Aqui está, quem sabe, um dos principais desafios para os profissionais de saúde: o estímulo à participação da sociedade no Sistema Único de Saúde, já que a Portaria 678, de 2006, do Ministério da Saúde, incita os profissionais da Estratégia de Saúde da Família a serem "indutores na promoção e estímulo à participação da comunidade no controle social, como característica do processo de trabalho de saúde da família". Atualmente, com a implantação dos Núcleos de Apoio à Saúde da Família - NASF ${ }^{10}$ em todo território nacional, amplia-se o escopo de ação da estratégia de saúde da família. Novos profissionais, como o assistente social, o psicólogo, o nutricionista, o educador físico, dentre outros, aparecem como fortalecedores e apoiadores das ações já

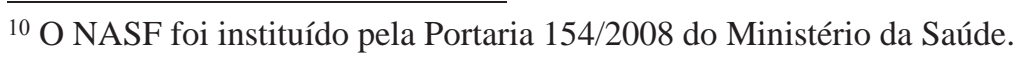

Serv. Soc. \& Saúde, Campinas, SP v. 11, n. 2 (14) p. 245-268 jul./dez. 2012 ISSN 1676-6806 
desenvolvidas ou daquelas que os profissionais da estratégia, por falta ou necessidade de um conhecimento mais específico, não assumiam como prioridade em suas ações.

Na pesquisa ora realizada, foi constatado certo afastamento dos profissionais da Estratégia de Saúde da Família dos conselhos locais, remetendo aos Agentes Comunitários de Saúde - ACS - mais uma tarefa, a de participar do conselho local de saúde, representando os segmentos dos profissionais da área, muitas vezes não possuindo outra escolha a não ser participar, ou melhor, se fazer presente. A narrativa de um/a conselheiro/a salienta a dificuldade de participação, como comentado anteriormente:

- Gostaria de... uma ajuda de como se conquista esse povo, os próprios funcionários... que é difícil para a gente conseguir; a gente busca o pessoal da comunidade e os próprios colegas da gente...” (2)

A participação no conselho local se torna mais eficiente e mais cheia de significados quando mobilizada pelo conhecimento da causa. Quais os objetivos dos conselhos locais de saúde? Qual a minha função nesse espaço? O que preciso saber minimamente para conseguir acompanhar as discussões e poder participar efetivamente do conselho? Quando perguntados sobre a participação em cursos ou atividades de capacitação na área da participação social e conselhos, apenas dois (22\%) dos nove entrevistados relataram a participação nesse tipo de evento, confirmando a falta de preparo e de instrumentos para uma participação efetiva.

A falta de capacitação deles confirma uma realidade brasileira e é uma causa significativa das limitações dos conselhos em seu trabalho cotidiano, sejam eles locais ou municipais. Estudo realizado com Conselhos Municipais de Saúde na grande Florianópolis enfatiza o "importante papel educativo que possuem os conselhos para se autoformarem e formarem a sociedade para experienciar essa prática política”. A autora refere-se aos espaços dos conselhos, como possibilitadores e mediadores do encontro entre intelectuais e massa, podendo este momento "contribuir para a passagem do senso comum ao bom senso, ou ao momento de consciência crítica" (KRUGER, 1997, p. 37).

\section{CONSIDERAÇÕES FINAIS}

Após uma incursão por inúmeras questões relacionadas à esfera dos conselhos locais de saúde, visualizadas e reconhecidas a partir das narrativas captadas nas 
entrevistas, é imprescindível interligá-las, aproximando-as, na tentativa de construir sentidos mais significativos para a literatura sobre o assunto.

Os conselhos pesquisados são espaços constituídos pela junção de forças tanto das unidades de saúde, através de seus representantes, quanto da participação da comunidade - os usuários do SUS -, uns e outros ainda envoltos pelas raízes do próprio processo de democratização do País, assim, em vias de construção. Marcados, mesmo que subliminarmente, por discursos e atos que questionam a possibilidade de configuração de um espaço múltiplo e com desejos coletivos, os conselheiros pesquisados ensaiam ações capazes de contribuir com a ampliação e efetivação do controle social junto aos conselhos de saúde em que atuam.

A pesquisa realizada, após um tempo de escuta e posterior reflexão, indica que a participação não tem sido um conceito colocado em prática nos bairros que sediam os conselhos estudados, pelo menos em relação à participação no espaço do conselho local, com dificuldades de se manter por falta de pessoal. O desafio é ainda maior, pois, além de necessitar da presença dos usuários, é fundamental que estejam qualificados para o exercício de tal função e a reconheçam diante da representação que fazem da coletividade. Também é preciso repensar as atuais formas de sensibilização para a participação, identificando e intervindo sobre os principais fatores que dificultam a “chegada" e/ou a permanência da população no conselho local de saúde, alguns já enfatizados nas narrativas dos conselheiros.

Em relação ao entendimento e ao exercício do controle social por parte dos conselheiros, apesar de não terem clareza sobre o significado do conceito, muitos o exercitam cotidianamente no conselho do qual participam ou mesmo no contato direto com a unidade de saúde. Embora não tenham acesso às informações relativas às movimentações orçamentárias, as ações de controle social por eles praticadas influem na gestão das unidades de saúde, principalmente nas proposições de execução dos seus serviços. Se reconhecermos o controle social como a possibilidade de participar da gestão do SUS, ainda que em esfera local, pode-se afirmar que, mesmo limitados, os conselhos pesquisados experimentam diferenciadas formas desse controle.

O grande desafio contemporâneo, tanto para os profissionais de saúde, quanto para os próprios usuários do SUS, é o de reinventar os conselhos locais, potencializando-os como espaços privilegiados dos quais a comunidade se sinta parte, entenda seu conteúdo e vislumbre o usufruto dos bens, agora coletivos, dentre eles o 
direito à saúde. Portanto, o conselho é lugar de apropriação, pela comunidade, de um bem público: a saúde. O conselho local necessita ser um dispositivo marcado pela vontade de participar da comunidade e dos profissionais de saúde. Agradável ao convívio, às trocas de experiências e, de consequência, à aprendizagem. Enfim, ambientes que possuam e produzam energia capaz de contribuir com a política local, que vislumbre como fim a saúde integral e universal, presente na lei orgânica de saúde.

Os conselhos locais, como espaços de produção de política, nunca estarão prontos, pois são formados por pessoas e o inacabamento é condição que as caracteriza como seres humanos. Portanto, os conselhos são obras inacabadas, ora rascunhadas, ora com traços já bastante definidos, mas sempre com grande potencial de continuar sendo um lugar de construção coletiva, onde a diferença é positiva.

Esta pesquisa, além dos dados que apresenta, indica os conselhos locais de saúde como campo rico para o desenvolvimento de estudos, com os quais uma série de outras questões possa ser explorada, como a legitimidade das representações, a relação dos conselhos locais com o Conselho Municipal de Saúde, a relação entre os próprios conselhos locais e suas redes de relações, os jogos de poder e suas influências sobre as ações de saúde, entre outras questões que se possam observar, captar e vivenciar nesses espaços, desafios para próximas caminhadas.

\section{REFERÊNCIAS}

BARDIN, L. Análise de Conteúdo. São Paulo: Martins Fontes, 1977.

BARROS, E. D. Os Conselhos de Saúde e a responsabilidade cidadã. Ciência \& Saúde Coletiva. Rio de Janeiro, v. 3, n. 1, 1998. p. 18-19.

BORDENAVE, J. E. D. O que é participação. Coleção Primeiros Passos. São Paulo, SP: Editora Brasiliense, 1983.

BOSI, M. L.M.; MERCADO-MARTÍNEZ, F. (Orgs). Pesquisa qualitativa nos Serviços de Saúde. Petrópolis/RJ: Vozes, 2007.

BRASIL. Ministério da Saúde. Lei Federal n. 8.080, de 19 de setembro de 1990. Dispõe sobre o Sistema Único de Saúde - SUS. Brasília, 1990.

BRASIL. Lei Federal 8.142 de 28 de dezembro de 1990. Dispõe sobre a participação da comunidade no SUS e sobre as transferências intergovernamentais de recursos financeiros na área da saúde. Brasília, 1990. 
BRASIL. Portaria n $\mathbf{n}^{\mathbf{1}}$ 154, de 24 de janeiro de 2008. Cria os Núcleos de Apoio a Saúde da Família - NASF. Brasília, 2008.

BRASIL. Portaria n ${ }^{\mathbf{0}}$ 648/GM de 28 de março de 2006. Aprova a Política Nacional de Atenção Básica e estabelece a revisão de diretrizes e normas para a organização da Atenção Básica para os Programas Saúde da Família (PSF) e Programa Agentes Comunitários de Saúde (PACS). Brasília, 2006.

BRAVO, M. I. S. Participação social e controle social. In: Bravo, M. I. S.; MATOS, M. C. de; ARAÙJO, P. S. X. de (Org). Capacitação para Conselheiros de Saúde - textos de apoio. Rio de Janeiro: UERJ/NAPE, v. 1, 2001. p. 77-84.

CAMPOS, E. B.; MACIEL, C. A. B. Conselhos Paritários: o enigma da participação e da construção democrática. Serviço Social \& Sociedade, n. 55. São Paulo: Cortez, 1997. p. 143-55.

CARVAlHO. M do C. A. A. Participação Social no Brasil de Hoje. In: PÓLIS: Assessoria, Formação e Estudos em Políticas Sociais. São Paulo: PAPERS, 1998.

COHN, A.; ELIAS, P.; JACOBI, P. Participação popular e gestão de serviços de saúde: um olhar sobre a experiência do município de São Paulo. Saúde em Debate. Rio de Janeiro, n. 38, 1993. p. 90-3.

CORREIA, M. V.C. Que controle social? Os conselhos de saúde como instrumento.

Rio de Janeiro: Editora Fio Cruz, 2000.

COTTA, R.M. M.; CAZAL, M. de M.; RODRIGUES, J. F. de C. Participação, Controle

Social e Exercício da Cidadania: a (des) informação como obstáculo à atuação dos conselheiros de saúde. Physis: Revista de Saúde Coletiva. v. 19, n. 2. Rio de Janeiro, 2009.

ESCOREL, S.; MOREIRA, M. R. Participação Social. GIOVANELLA, L. (Org). Políticas e Sistema de Saúde no Brasil. Rio de Janeiro: Editora Fio Cruz, 2008. p. 9791.010 .

FLORIANÓPOLIS. Secretaria Municipal de Saúde. Conselho Municipal de Saúde -

CMS. Resolução nº 010/CMS/2008. Florianópolis/SC, 2008.

FLORIANÓPOLIS. Plano Municipal de Saúde de Florianópolis (PMS) 2007 - 2010. Florianópolis: 2007.100 p.

GEERTZ, C. A interpretação das culturas. Rio de Janeiro: LTC, 1989.

GIL, A. C. Métodos e técnicas da pesquisa social. São Paulo, Atlas, 4. ed., 1994. 


\section{INSTITUTO BRASILEIRO DE GEOGRAFIA E ESTATÍSTICA (IBGE). Censo}

Demográfico 2008. DISPONÍVEL EM: <

EM: 20 ABR. 2010.

KRUGER, T. R. Conselho de Saúde: as relações no exercício de deliberar e controlar. Katálysis. Florianópolis, n. 1, jun.2007. p. 28-39.

MINAYO, M. C. de S. (Org.). Pesquisa social: teoria, método e criatividade. Petrópolis/RJ: Vozes, 1994.

PÉRET, T. C. O Programa Saúde da Família: Questões e perspectivas. A experiência desenvolvida no Município de Campina Grande/PB. 2001. Dissertação (Mestrado) Pontifícia Universidade Católica do Rio de Janeiro (PUC-RJ) - Rio de Janeiro.

RAICHELIS, R. Esfera Pública e Conselhos de assistência social: caminhos da construção democrática. São Paulo: Cortez, 1998.

RAICHELIS, R. Organização e gestão das políticas sociais no Brasil. Cadernos de Capacitação em Serviço Social e Política Social, Mod. 03. Brasília: UnB/CEAD, 2000. p. 58-70.

SANTIAGO, I. M. F. L.; LACERDA, W.A DE. A participação popular na gestão local do Programa Saúde da Família em Campina Grande, Paraíba. Katálysis. Florianópolis, V. 10, N. 2 p. 197-205 (jul./dez. 2007).

SILVA, M. S. DA. Conselhos Municipais dos Direitos da Criança e do Adolescente do Médio Vale do Itajaí/SC: o perfil, o conteúdo e os organizadores da agenda. 2000. Dissertação (mestrado em Sociologia Política - UFSC/CFH - Florianópolis. VIANNA, M. L. T. W.; CAVALCANTI, M. L.; CABRAL, M. P. Participação em saúde: do que estamos falando? Sociologias. Porto Alegre, A. 11, N. 21, jan./jun. 2009, p. 218-51. 
